\title{
Multiple major retinal vascular occlusions in sickle cell haemoglobin $\mathrm{C}$ disease
}

\author{
AMRESH CHOPDAR \\ Western Ophthalmic Hospital, London
}

Vascular occlusions in the peripheral retina are a common complication of sickle cell haemoglobinopathy (Goldberg 197I; Condon and Serjeant, 1972a). Occlusions in the central area of the retina involving the major retinal arterial arcade are uncommon, but they have been reported (Knapp, 1972; Condon and Serjeant, 1972b; Acacio and Goldberg, 1973) in patients suffering from sickle cell anaemia (SS), and also (Kabakow, van Weimokly, and Lyons, 1955; Welch and Goldberg, 1966; Conrad and Penner, 1967) in patients with the sickle cell carrier state (AS).

Goodman, von Sallmann, and Holland (1957), and Acacio and Goldberg (1973) have reported cases of multiple vascular occlusions occurring in different sized arterioles in and around the posterior pole of the fundus in patients with sickle cell anaemia.

A case of multiple vascular occlusions of both larger and smaller sized retinal arterioles occurring simultaneously in a patient with sickle cell haemoglobin $\mathrm{C}$ disease (SC) described in this paper is believed to be the first such case to be reported.

\section{Case report}

A 22-year-old West Indian man presented at the Western Ophthalmic Hospital suffering from sudden loss of vision in the right eye during the previous 6 hours.

He had been seen 3 months earlier for a routine check-up after being referred by his general practitioner. At that time his best corrected visual acuity was 6/9 in both eyes. There was no obvious retinopathy, except two spots of pigmented chorio-retinal change at the temporal periphery of the right eye. He had been in hospital twice before for abdominal and bone pain.

\section{PHYSICAL EXAMINATION}

The patient had good physical health and no signs of sickle cell crisis. He had a pulse rate of $72 / \mathrm{min}$, blood pressure $95 / 60 \mathrm{~mm} \mathrm{Hg}$, no bruits in the neck, and no murmur in the heart. The abdominal, respiratory, and central nervous systems were normal. No source of embolization was found.

\section{LABORATORY INVESTIGATIONS}

The haematological examination showed a haemoglobin of $13.5 \mathrm{~g}$ per cent, mean corpuscular volume $95 \mu^{3}$, mean corpuscular haemoglobin $33.1 \mathrm{pg}$, mean corpuscular haemoglobin concentration $34.4 \mathrm{~g}$ per cent, and numerous target and contracted cells in the blood film. The haemoglobin electrophoresis showed HbS-HbC separation, thus confirming this to be a case of sickle cell $\mathbf{C}$ disease.

\section{OCULAR FINDINGS}

The right visual acuity was hand movements only and the left was $6 / 12$, with $-2 \cdot 75 \mathrm{D}$ sph., $-1 \cdot 25 \mathrm{D}$ cyl., axis $5^{\circ}$. The right visual field showed a central scotoma extending nasally and some constriction of the nasal periphery. The right pupillary response to direct light was sluggish, but there was a normal response to indirect illumination. Both eyes were white and quiet. The lens and vitreous were clear in both eyes.

The right fundus showed areas of patchy cloudy swelling of the retina at the posterior pole, with a cherry red spot at the macula. Both the superior and inferior temporal branches of the central retinal artery were found to be occluded separately, each at a point about $2 \frac{1}{2}$ disc diameters away from the nerve head. There was a large macular branch arising from the superior division of the central retinal artery, running just above the macula which was also occluded about the same distance from the optic disc. In addition there were several smaller branches occluded around the macular area. The retinal vasculature was poorly defined beyond the mid-equatorial region on the temporal half. There were two chorio-retinal 'sun burst' lesions at this part of the fundus but no other lesion of SC disease was seen, Fig. I.

The left fundus showed two pigmented chorioretinal lesions at the periphery and a round red area one-half disc diameter above the optic disc.

A fluorescein angiogram was performed 24 hours after the onset of symptoms. Early transit showed complete occlusion of the three major retinal arterial branches which had been clinically observed, together with a number of individual smaller arterioles around the posterior pole. During the transit no dye was seen to return via the corresponding venules and veins, and 
FIG. I Right fundus 24 hours after onset of symptoms showing multiple vascular occlusions with cloudy swelling and cherry red spot at macula

there was complete lack of capillary perfusion. During the late phase the junctional areas between the patent and occluded arterioles showed an increase in fluorescence, but there was no leakage of dye at any stage (Fig. 2).

\section{Course}

Three weeks after the episode the visual acuity had improved to counting fingers, and the visual fields remained unchanged. Some of the occluded arterioles were turning white distal to their occlusions, giving a silver wiring appearance. Several round red areas were now appearing in close relation to the site of occlusion. One in relation to the larger macular branch showed a very deep red colour and a light top, giving the impression of a retinal hole with operculum. The other two were in relation to the infero-temporal vessels. One of these red areas showed a rather curious appearance. It was red in the centre and periphery while the middle zone was completely free from red cells and looked whitish-grey. The central red area had a flat top.

Three months later the visual acuity in the right eye had improved to $6 / 24$ with a correction of $-3.5 \mathrm{D}$ sph., $-\mathrm{I} \mathrm{D}$ cyl., axis $180^{\circ}$. The central scotoma, cloudy swelling, and round red areas had 


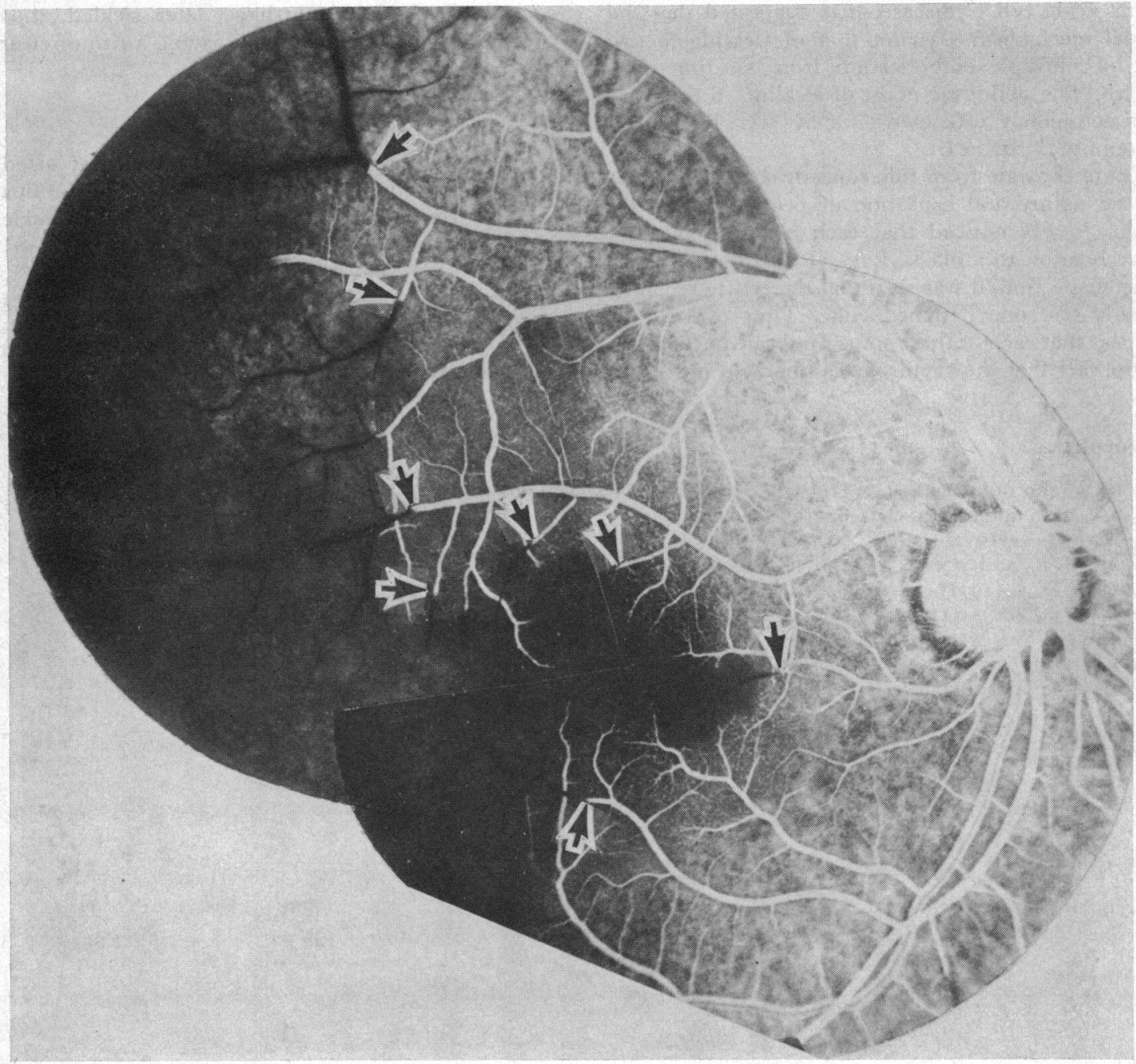

FIG. 2 Composite fundus picture of right eye from fluorescein angiogram performed 24 hours after onset of symptoms showing complete occlusion of three major retinal arterial branches together with number of individual smaller arterioles around posterior pole (some indicated by arrows)

disappeared, but the occluded vessels showed an increase in whitening. Fluorescein angiography could not be done at these stages as the patient refused to have the injection.

\section{Comments}

The cloudy swelling and the cherry red spot seen in this patient are typical of retinal artery occlusion. The absence of cloudy swelling and normal fluorescein pattern on the nasal side support the view that the obstruction was limited to the temporal half of the retina. The multiplicity and the sites of the occlusions near bifurcations suggest embolism, but multiple foci of sickling cannot be ruled out, although it seems unlikely that such numerous foci could occur simultaneously. It is suggested that an embolus of sickled erythrocytes was formed at an undetermined point in the circulation, became dislodged, and fragmented, blocking a number of different sized retinal arterioles. The highly fluorescent spots seen in the late stage of these angiograms at the occluded junctions are probably due to the pooling of dye in the clear plasma. Absence of dye in the corresponding veins is additional evidence of lack of perfusion of the retina.

Although this patient showed multiple foci of arteriolar occlusion, and was known to be suffering 
from sickle cell $\mathrm{C}$ disease, it is suggested that the actual mechanism was not that of sickling in situ but of multiple embolization from sickling elsewhere. The definitive point of sickling in this case was completely unknown; it may even have been as remote as the heart.

Quite separate from this concept is consideration of the nature and causation of peculiar large red spots. It was noticed that each occurred in very close relation to a blocked vessel. Furthermore, on close inspection, it was seen that the centre red spot usually had one flattened edge. Thus one would suspect that each of these spots might be due simply to the fact that the erythrocytes liberated into each such subhyaloid haemorrhage, later sickled, thus contracting into a sort of ball leaving a rim of clear plasma around.

\section{Summary}

A case of multiple occlusions of different sized arterioles involving the central area of the fundus has been reported in a patient suffering from sickle cell haemoglobin $\mathrm{C}$ disease (SC).

My thanks are due to Mr Redmond J. H. Smith for his guidance and assistance in preparing the manuscript, and to Mr S. Young of the Royal College of Surgeons for the illustrations.

\section{References}

ACACio, I., and Goldberg, M. F. (1973) Amer. Y. Ophthal., 75, 86r

CONDON, P. I., and SERJEANT, G. R. (1972a) Ibid., 73, 533

$\longrightarrow$ (1972b) Ibid., 74, 921

CONRAD, W. C., and PENNER, R. (I967) Ibid., 63, 465

GOLDBERG, M. F. (1971) Arch. Ophthal., 85, 428

GOODMAN, G., VON SAlLMANN, L., and hollaND, M. G. (1957) Ibid., 58, 655

KABAKOW, B., VAN WEIMOKLY, S. S., and LYONS, H. (1955) Ibid., 54, 670

KNAPP, J. W. (1972) Amer. F. Ophthal., 73, 857

WELCH, R. B., and GOLDBERG, M. F. (1966) Arch. Ophthal., 75, 353 